\title{
Effect of fundholding and indicative prescribing schemes on general practitioners' prescribing costs
}

\author{
Jean Bradlow, Angela Coulter
}

\begin{abstract}
Objective-To compare general practitioners' prescribing costs in fundholding and non-fundholding practices before and after implementation of the NHS reforms in April 1991.

Design-Analysis of prescribing and cost information (PACT data; levels 2 and 3 ) over two six month periods in 1991 and 1992.
\end{abstract}

Setting-Oxford region.

Participants-Three dispensing fundholding practices; five non-dispensing fundholding practices; and seven non-dispensing, non-fundholding practices.

Main outcome measures-Percentage change in net cost of ingredients, number of items prescribed, average cost per item, and proportion of generic drugs prescribed after NHS reforms.

Results-Prescribing costs increased in all practices in the six months after the reforms. The net costs of ingredients increased among dispensing fundholders by $10 \cdot 2 \%$, among non-dispensing fundholders by $13 \cdot 2 \%$, and among non-fundholders by $18 \cdot 7 \%$. The number of items prescribed also increased in all three groups (by $5 \cdot 2 \%, 7 \cdot 5 \%$, and $6 \cdot 1 \%$ respectively). The increase in average cost per item was $4 \cdot 8 \%$ for dispensing fundholders, $5 \cdot 3 \%$ for non-dispensing fundholders, and $11.9 \%$ for nonfundholders. Dispensing fundholders increased the proportion of generic drugs prescribed from 26.9\% $44.5 \%$ to $48 \cdot 7 \%$; non-fundholders showed no change $(47 \%)$. Five of the eight fundholding practices made savings in their drugs budgets at the end of the first year of fundholding (range 2.9-10.7\%; the three other practices overspent by up to $3 \cdot 6 \%$ ). All nonfundholding practices exceeded their indicative prescribing amounts (range $3 \cdot 2-20 \cdot 0 \%$ ).

Conclusions-Fundholding has helped to curb increases in prescribing costs, even among dispensing general practitioners, for whom the incentives are different. Indicative prescribing amounts for non-fundholding practices do not seem to have had the same effect.

Health Services Research Unit, Department of Public Health and Primary Care, University of Oxford,

Radcliffe Infirmary, Oxford OX2 6HE

Jean Bradlow, research officer

Angela Coulter, director

Correspondence to:

Ms Bradlow.

$B M 7$ 1993;307:1186-9

The total cost of NHS prescriptions dispensed by pharmacists and appliance contractors in the United Kingdom in 1991 was over $\$ 3000 \mathrm{~m}$. This figure represented an average cost of $£ 55$ per person and was the largest single element of the family health services authorities' budget. In the past decade there has been a rise, after inflation, of $56 \%$ in the net costs of ingredients and $26 \%$ in the number of items prescribed.

The government saw these escalating drug costs as a priority to be addressed in its reorganisation of the NHS and introduced two initiatives designed to provide general practitioners with incentives to reduce to $34.5 \%$ and non-dispensing fundholders from

prescribing costs: indicative prescribing amounts for non-fundholding general practices and prescribing budgets for fundholding practices. Family health services authorities were responsible for setting indicative prescribing amounts based on previous spending adjusted for price rises and changes in product mix, expected changes in the size of a practice's population, changes in the number of patients who require expensive drugs, and the average amount spent in comparable practices in the authority. They were expected to monitor what was spent against indicative amounts and to encourage cost effective prescribing. ${ }^{2}$ An incentive scheme for non-fundholders was also proposed: if a majority of practices in a family health services authority could agree planned savings the authority was allowed to keep half of the savings for "schemes of improvement in primary health care in their areas as agreed with their general practitioners." This scheme, however, did not attract much interest and none of the family health services authorities in the Oxford region took part in it.

Fundholders' drugs budgets were calculated on the same basis as indicative precribing amounts, with additional adjustments for discounts and container costs to convert the indicative amount into a cash budget. The budgets were cash limited and any savings made could either be transferred into another budget category-for example, hospital services-or spent on improving patient care in the next financial year. These budgets offered a more direct incentive to general practitioners to save money.

The effects of these two initiatives need to be properly compared and evaluated. In this paper we report some results from a study designed to evaluate the impact of the NHS reforms on general practices in the Oxford region. We have collected data from first wave fundholding practices and non-fundholding practices in the year before and the year after the 1991 reorganisation to measure the effect of the NHS reforms on outpatient referral rates, inpatient admissions, prescribing patterns, and practice based facilities. This paper reports the general practitioners' prescribing patterns and costs.

\section{Introduction}

\section{Methods}

Prescribing analysis and cost (PACT) data, levels 2 and 3, were obtained for two six month periods in 1990-1 (phase 1) and in 1991-2 (phase 2) for eight fundholding and seven non-fundholding practices. These practices included all but two of those which had participated in a previously reported referral study. ${ }^{4}$ The remaining two practices were excluded because their family health services authority was unable to supply PACT data for the relevant six months of phase 1.

The aim was to monitor changes in prescribing costs, the number of items prescribed, and the propor- 
tion of generic drugs prescribed over the two time periods in three groups of practices-non-dispensing, non-fundholding practices; non-dispensing, fundholding practices; and dispensing fundholding practices. The dispensing practices were analysed separately because the incentives for dispensing general practitioners are different in that they retain the profits from their dispensary. ${ }^{5}$ Additionally, there were no dispensing practices among the non-fundholding group.

The total population registered with the practices taking part in the study was 208398 . Practice populations ranged from 6255 to 24008 , with a mean of 13739 in the fundholding practices and of 14227 in the non-fundholding practices. Six of the eight fundholding practices and six of the seven non-fundholding practices were training practices. All but one nonfundholding practice had computers. None of the practices were in deprived areas and none received a deprivation allowance for any of their patients.

Results are expressed as a six monthly rate per 1000 prescribing units. Prescribing units are used in PACT data as a crude means of adjusting for age. They are based on the assumption that older patients receive on average three times as many prescriptions as other patients and, since the number of elderly patients in a practice varies, the denominator is the number of prescribing units rather than the practice population.
Details of indicative prescribing amounts and fundholders' drugs budgets were obtained so that the budget and the amount spent at the end of the year could be compared. Questionnaires were sent to all participating practices asking whether they had used any formularies or prescribing protocols before the 1991 reorganisation, whether any formularies or prescribing protocols had been introduced during the first year of the reforms, and whether the practice had sought pharmaceutical advice either from the family health services authority or from the regional health authority.

\section{Results}

The dispensing fundholders had the highest total net cost of ingredients in the first phase of the study but the lowest in the second phase, despite an increase of $10 \cdot 2 \%$ between the two periods (table I). The net costs of ingredients increased more steeply among the non-dispensing practices. The greatest increase occurred in prescribing for diseases of the central nervous system and the smallest in prescribing for musculoskeletal problems.

All groups increased the number of items prescribed (table II), and the average cost per item also increased in all three groups (table III). The percentage of generic drugs prescribed increased significantly in

TABLE I-Total net costs of ingredients $(f)$ per 1000 prescribing units in the two study periods by therapeutic group and type of general practice

\begin{tabular}{|c|c|c|c|c|c|c|c|c|c|}
\hline \multirow[b]{3}{*}{ Therapeutic group } & \multicolumn{6}{|c|}{ Fundholding } & & & \\
\hline & \multicolumn{3}{|c|}{ Dispensing } & \multicolumn{3}{|c|}{ Non-dispensing } & \multicolumn{3}{|c|}{ Non-fundholding, non-dispensing } \\
\hline & Phase 1 & Phase 2 & $\begin{array}{l}\% \text { Change } \\
\text { (95\% confidence interval) }\end{array}$ & Phase 1 & Phase 2 & $\begin{array}{c}\% \text { Change } \\
\text { (95\% confidence interval) }\end{array}$ & Phase 1 & Phase 2 & $\begin{array}{c}\% \text { Change } \\
\text { (95\% confidence interval) }\end{array}$ \\
\hline $\begin{array}{l}\text { Gastrointestinal } \\
\text { Cardiovascular } \\
\text { Respiratory } \\
\text { Central nervous system } \\
\text { Infections } \\
\text { Musculoskeletal } \\
\text { Other }\end{array}$ & $\begin{array}{r}1947 \\
2903 \\
1962 \\
1330 \\
1523 \\
171 \\
4132\end{array}$ & $\begin{array}{l}2195 \\
3125 \\
2278 \\
1702 \\
1456 \\
1485 \\
4853\end{array}$ & $\begin{array}{c}12.7(11.8 \text { to } 13.5) \\
7.6(7.0 \text { to } 8.3) \\
16.1(15.3 \text { to } 17.0) \\
27.9(26.8 \text { to } 28.9) \\
-4 \cdot 4(-5.4 \text { to }-3.4) \\
-13.2(-14.1 \text { to }-12.3) \\
17.5(17.0 \text { to } 18.0)\end{array}$ & $\begin{array}{l}1502 \\
3050 \\
2337 \\
1296 \\
1290 \\
1161 \\
4594\end{array}$ & $\begin{array}{l}1745 \\
3286 \\
2644 \\
1592 \\
1319 \\
1171 \\
5483\end{array}$ & $\begin{array}{c}16.2(15.5 \text { to } 16.9) \\
7.7(7.3 \text { to } 8.2) \\
13.1(12.6 \text { to } 13.7) \\
22.8(21.9 \text { to } 23.5) \\
2.3(1.5 \text { to } 3.0) \\
0.9(0.1 \text { to } 1.7) \\
19.4(19.0 \text { to } 19.7)\end{array}$ & $\begin{array}{l}1804 \\
2580 \\
2055 \\
1395 \\
1423 \\
1225 \\
4670\end{array}$ & $\begin{array}{l}2143 \\
2876 \\
2376 \\
1727 \\
1697 \\
1273 \\
5889\end{array}$ & $\begin{array}{c}18.8(18.3 \text { to } 19.4) \\
11.5(11.0 \text { to } 11.9) \\
15.6(15.1 \text { to } 16.1) \\
23.9(23.2 \text { to } 24.6) \\
19.3(18.7 \text { to } 19.9) \\
3.9(3.2 \text { to } 4.6) \\
26.1(25.9 \text { to } 26.3)\end{array}$ \\
\hline Total & 15508 & 17093 & $10.2(9.9$ to 10.5$)$ & 15229 & 17239 & $13.2(13.0$ to 13.4$)$ & 15151 & 17983 & $18.7(18.4$ to 18.8$)$ \\
\hline
\end{tabular}

*Includes drugs, dressings, and appliances. $\quad$ Percentage change may not correspond as a result of rounding.

TABLE II-Number of items per 1000 prescribing units in the two study periods by therapeutic group and type of general practice

\begin{tabular}{|c|c|c|c|c|c|c|c|c|c|}
\hline \multirow[b]{3}{*}{ Therapeutic group } & \multicolumn{6}{|c|}{ Fundholding } & & & \\
\hline & \multicolumn{3}{|c|}{ Dispensing } & \multicolumn{3}{|c|}{ Non-dispensing } & \multicolumn{3}{|c|}{ Non-fundholding, non-dispensing } \\
\hline & Phase 1 & Phase 2 & $\begin{array}{c}\% \text { Change } \\
\text { (95\% confidence interval) }\end{array}$ & Phase 1 & Phase 2 & $\begin{array}{c}\% \text { Change } \\
\text { (95\% confidence interval) }\end{array}$ & Phase 1 & Phase 2 & $\begin{array}{l}\% \text { Change } \\
\text { (95\% confidence interval) }\end{array}$ \\
\hline $\begin{array}{l}\text { Gastrointestinal } \\
\text { Cardiovascular } \\
\text { Respiratory } \\
\text { Central nervous system } \\
\text { Infections } \\
\text { Musculoskeletal } \\
\text { Other* }\end{array}$ & $\begin{array}{l}178 \\
361 \\
207 \\
386 \\
305 \\
162 \\
665\end{array}$ & $\begin{array}{l}191 \\
382 \\
219 \\
390 \\
309 \\
159 \\
730\end{array}$ & $\begin{array}{l}7.4(4.6 \text { to } 10.3) \\
5.8(4.0 \text { to } 7.6) \\
6.1(3.5 \text { to } 8.7) \\
0.9(-0.8 \text { to } 2.5) \\
1.3(-0.5 \text { to } 3.4) \\
-1.8(-4.8 \text { to } 1.2) \\
9.8(8.9 \text { to } 10.7)\end{array}$ & $\begin{array}{l}156 \\
335 \\
223 \\
327 \\
319 \\
128 \\
745\end{array}$ & $\begin{array}{l}169 \\
348 \\
246 \\
346 \\
339 \\
137 \\
815\end{array}$ & $\begin{array}{c}8.7(6.5 \text { to } 10.9) \\
3.8(2.5 \text { to } 5.1) \\
10.4(8.7 \text { to } 12.2) \\
5.6(4.3 \text { to } 7.0) \\
6.2(4.8 \text { to } 7.6) \\
7.2(4.7 \text { to } 9.6) \\
9.4(8.9 \text { to } 9.9)\end{array}$ & $\begin{array}{l}161 \\
277 \\
191 \\
333 \\
317 \\
125 \\
674\end{array}$ & $\begin{array}{l}170 \\
291 \\
213 \\
339 \\
327 \\
127 \\
737\end{array}$ & $\begin{array}{c}5.5(3.6 \text { to } 7.3) \\
5.0(3.7 \text { to } 6.3) \\
11.6(9.9 \text { to } 13.2) \\
1.9(0.8 \text { to } 3.0) \\
3.2(2.0 \text { to } 4.4) \\
1.7(-0.4 \text { to } 3.8) \\
9.4(8.9 \text { to } 10.0)\end{array}$ \\
\hline Total & 2264 & 2380 & $5 \cdot 2(4.4$ to $5 \cdot 9)$ & 2234 & 2401 & $7.5(7.0$ to 8.0$)$ & 2078 & 2205 & $6 \cdot 1(5.6$ to 6.6$)$ \\
\hline
\end{tabular}

^Includes drugs, dressings, and appliances. $\quad$ Percentage change may not correspond as a result of rounding.

TABLE III-Average cost per item $(£)$ in the two study periods by therapeutic group and type of general practice

\begin{tabular}{|c|c|c|c|c|c|c|c|c|c|}
\hline \multirow[b]{3}{*}{ Therapeutic group } & \multicolumn{6}{|c|}{ Fundholding } & & & \\
\hline & \multicolumn{3}{|c|}{ Dispensing } & \multicolumn{3}{|c|}{ Non-dispensing } & \multicolumn{3}{|c|}{ Non-fundholding, non-dispensing } \\
\hline & Phase 1 & Phase 2 & $\begin{array}{c}\% \text { Change } \\
\text { (95\% confidence interval) }\end{array}$ & Phase 1 & Phase 2 & $\begin{array}{c}\% \text { Change } \\
\text { (95\% confidence interval) } \\
\end{array}$ & Phase 1 & Phase 2 & $\begin{array}{c}\% \text { Change } \\
\text { (95\% confidence interval) }\end{array}$ \\
\hline $\begin{array}{l}\text { Gastrointestinal } \\
\text { Cardiovascular } \\
\text { Respiratory } \\
\text { Central nervous system } \\
\text { Infections } \\
\text { Musculoskeletal } \\
\text { Other }\end{array}$ & $\begin{array}{r}10.95 \\
8.04 \\
9.50 \\
3.44 \\
4.99 \\
10.57 \\
6.22\end{array}$ & $\begin{array}{r}11 \cdot 49 \\
8 \cdot 18 \\
10 \cdot 39 \\
4 \cdot 37 \\
4 \cdot 71 \\
9 \cdot 34 \\
6 \cdot 65\end{array}$ & $\begin{array}{c}4.9(4.0 \text { to } 5 \cdot 8) \\
1.7(1.4 \text { to } 2 \cdot 1) \\
9 \cdot 4(8.5 \text { to } 10.3) \\
27.0(25.9 \text { to } 27.8) \\
-5.8(-6.5 \text { to }-5 \cdot 0) \\
-11.6(-12.5 \text { to }-10.7) \\
6.9(6.6 \text { to } 7.4)\end{array}$ & $\begin{array}{r}9 \cdot 63 \\
9 \cdot 10 \\
10 \cdot 49 \\
3.96 \\
4 \cdot 04 \\
9.06 \\
6 \cdot 17\end{array}$ & $\begin{array}{r}10 \cdot 30 \\
9 \cdot 44 \\
10.75 \\
4 \cdot 60 \\
3 \cdot 89 \\
8.53 \\
6.73\end{array}$ & $\begin{array}{l}6.9(6.2 \text { to } 7.6) \\
3.8(3.3 \text { to } 4.3) \\
2.5(1.9 \text { to } 3.0) \\
16 \cdot 2(15.4 \text { to } 17.0) \\
-3.7(-4.3 \text { to }-3.1) \\
-5.8(-6.1 \text { to }-5.6) \\
9.1(8.8 \text { to } 9.4)\end{array}$ & $\begin{array}{r}11 \cdot 19 \\
9 \cdot 30 \\
10 \cdot 78 \\
4 \cdot 19 \\
4 \cdot 49 \\
9 \cdot 78 \\
6 \cdot 93\end{array}$ & $\begin{array}{r}12 \cdot 61 \\
9.87 \\
11 \cdot 17 \\
5.09 \\
5 \cdot 19 \\
9.99 \\
7.99\end{array}$ & $\begin{array}{c}12 \cdot 7(12 \cdot 1 \text { to } 13 \cdot 2) \\
6 \cdot 2(6 \cdot 1 \text { to } 6 \cdot 3) \\
3 \cdot 6(3 \cdot 1 \text { to } 4 \cdot 1) \\
21 \cdot 5(21 \cdot 0 \text { to } 22 \cdot 1) \\
15 \cdot 6(15 \cdot 1 \text { to } 16 \cdot 1) \\
2 \cdot 1(2 \cdot 1 \text { to } 2 \cdot 2) \\
15 \cdot 2(15 \cdot 0 \text { to } 15 \cdot 4)\end{array}$ \\
\hline Total & 6.85 & $7 \cdot 18$ & $4 \cdot 8(4 \cdot 6$ to $5 \cdot 0)$ & $6 \cdot 82$ & $7 \cdot 18$ & $5 \cdot 3(5 \cdot 2$ to $5 \cdot 5)$ & $7 \cdot 29$ & $8 \cdot 16$ & $11.9(11.8$ to 12.0$)$ \\
\hline
\end{tabular}

*Includes drugs, dressings, and appliances. 


\begin{tabular}{|c|c|c|c|c|c|c|c|c|c|}
\hline \multirow[b]{3}{*}{ Generic construction } & \multicolumn{6}{|c|}{ Fundholding } & & & \\
\hline & \multicolumn{3}{|c|}{ Dispensing } & \multicolumn{3}{|c|}{ Non-dispensing } & \multicolumn{3}{|c|}{ Non-fundholding, non-dispensing } \\
\hline & Phase 1 & Phase 2 & $\begin{array}{c}\% \text { Change } \\
\text { (95\% confidence interval) }\end{array}$ & Phase 1 & Phase 2 & $\begin{array}{c}\% \text { Change } \\
\text { (95\% confidence interval) }\end{array}$ & Phase 1 & Phase 2 & $\begin{array}{c}\% \text { Change } \\
\text { (95\% confidence interval) }\end{array}$ \\
\hline $\begin{array}{l}\text { All drugs } \\
\text { Allopurinol for Zyloric } \\
\text { Naprofen for Naprosyn }\end{array}$ & $\begin{array}{l}26 \cdot 9 \\
52 \cdot 7 \\
13 \cdot 5\end{array}$ & $\begin{array}{l}34 \cdot 5 \\
64 \cdot 7 \\
46 \cdot 3\end{array}$ & $\begin{array}{l}7 \cdot 6(7 \cdot 2 \text { to } 8 \cdot 0) \\
12 \cdot 1(6 \cdot 2 \text { to } 17 \cdot 9) \\
32 \cdot 8(28 \cdot 8 \text { to } 37 \cdot 0)\end{array}$ & $\begin{array}{l}44 \cdot 5 \\
83 \cdot 8 \\
64 \cdot 4\end{array}$ & $\begin{array}{l}48 \cdot 7 \\
94 \cdot 2 \\
85 \cdot 1\end{array}$ & $\begin{array}{l}4.2(3.9 \text { to } 4.5) \\
10.4(7.0 \text { to } 13.8) \\
20.7(17.6 \text { to } 23.8)\end{array}$ & $\begin{array}{l}46 \cdot 5 \\
82 \cdot 9 \\
70 \cdot 9\end{array}$ & $\begin{array}{l}46 \cdot 6 \\
81 \cdot 3 \\
76 \cdot 5\end{array}$ & $\begin{array}{c}0.1(-0.2 \text { to } 0.4) \\
-1.6(-5.6 \text { to } 2.3) \\
5.6(2.6 \text { to } 8.7)\end{array}$ \\
\hline $\begin{array}{l}\text { Co-trimoxazole for Septrin or } \\
\text { Bactrim }\end{array}$ & $5 \cdot 0$ & $37 \cdot 3$ & $32.3(28.4$ to 36.2$)$ & $58 \cdot 3$ & 82.5 & $24.2(21.5$ to 26.9$)$ & $53 \cdot 1$ & $72 \cdot 1$ & $19.0(17.0$ to $21 \cdot 1)$ \\
\hline
\end{tabular}

TABLE V-Net costs of ingredients $(£)$ per 1000 prescribing units for each practice in the two study periods

\begin{tabular}{|c|c|c|c|}
\hline Practice No & Phase 1 & Phase 2 & $\begin{array}{c}\% \text { Increase } \\
\text { after } \\
\text { inflation (3\%) }\end{array}$ \\
\hline \multicolumn{4}{|c|}{ Fundholding } \\
\hline \multicolumn{4}{|l|}{ Dispensing: } \\
\hline 1 & 13989 & 15411 & $6 \cdot 9$ \\
\hline 2 & 15748 & 17304 & $6 \cdot 6$ \\
\hline 3 & 17553 & 19317 & 6.8 \\
\hline \multicolumn{4}{|c|}{ Non-dispensing: } \\
\hline 4 & 12680 & 14487 & $11 \cdot 0$ \\
\hline 5 & 14062 & 16109 & $11 \cdot 3$ \\
\hline 6 & 14279 & 16915 & $15 \cdot 2$ \\
\hline 7 & 17141 & 18061 & $2 \cdot 1$ \\
\hline 8 & 19336 & 22092 & 11.0 \\
\hline \multicolumn{4}{|c|}{ Non-fundholding } \\
\hline \multicolumn{4}{|c|}{ Non-dispensing: } \\
\hline 9 & 10765 & 12855 & $16 \cdot 1$ \\
\hline 10 & 13788 & 15877 & 11.9 \\
\hline 11 & 14983 & 18476 & $20 \cdot 0$ \\
\hline 12 & 15096 & 19001 & $22 \cdot 6$ \\
\hline 13 & 16221 & 19742 & $18 \cdot 4$ \\
\hline 14 & 17672 & 19204 & $5 \cdot 4$ \\
\hline 15 & 17781 & 20617 & $12 \cdot 7$ \\
\hline
\end{tabular}

both fundholding groups but remained almost constant in the non-fundholding practices (table IV). Three pairs of drugs were used to analyse specific changes in general prescribing: substitution of allopurinol for Zyloric, naproxen for Naprosyn, and co-trimoxazole for Septrin or Bactrim. These particular groups of drugs were among those recommended as priorities for generic substitution both by medical advisers to the family health services authorities and by the regional pharmaceutical adviser. The most dramatic changes occurred among dispensing fundholders, but their rate of use of generic drugs remained much lower than those of non-dispensing fundholders or non-fundholders.

Five of the eight fundholding practices and two of the non-fundholding practices reported that they were trying to increase the proportion of generic drugs prescribed. Seven of the fundholding practices had developed practice formularies. Six of these had been introduced since the practices became fundholding. Only two of the seven non-fundholding practices had a formulary. Six of the fundholding practices and five of the non-fundholding practices had received prescribing advice from either the medical adviser to their family health services authority or the regional prescribing adviser for primary care.

Table $\mathrm{V}$ shows the percentage changes in the net costs of ingredients for each practice after allowing $3.3 \%$ for inflation between 1990 and 1991 . This figure includes the estimated growth in prices $(1 \cdot 7 \%)$ and the growth due to new products $(1.6 \%) .^{6}$ None of the practices achieved a reduction in the total net costs of ingredients during the study.

The 1991-2 indicative prescribing amounts and fundholders' budgets were based on PACT data for 1989-90 adjusted according to Department of Health guidelines. In the Oxford region practices whose prescribing costs were below the average in the family health services authority also had their budgets increased by $50 \%$ of the difference between their prescribing costs and the average in the authority for the first year of fundholding. Five fundholding practices in the study received this increment.

Five of the fundholding practices made savings on their drugs budgets, whereas all the non-fundholding practices overspent their indicative prescribing amounts (table VI). The fundholders' savings on the drugs element of their budgets ranged from $£ 12103$ to $£ 89755$ per practice. (These figures are derived from audited fundholding amounts.) Two of the practices transferred planned savings into other budget headings during the financial year 1991-2. One practice's drugs budget saving was transferred at the end of the year to pay off a deficit on the hospital services budget. The remaining fundholding practices spent a total of $£ 114253$ on improving practice premises, buying equipment, employing staff, and purchasing additional elective procedures to reduce waiting lists.

TABLE VI-Prescribing budgets for 1991-2 per 1000 prescribing units and amount spent $(£)$ for each practice

\begin{tabular}{lccc}
\hline Practice No & Budget & Amount spent & \% Difference \\
\hline \multicolumn{4}{c}{ Fundholding * } \\
Dispensing: & \multicolumn{3}{c}{} \\
1 & 28731 & 27483 & $-4 \cdot 3$ \\
2 & 32052 & 31138 & $-2 \cdot 9$ \\
3 & 33171 & 34367 & $3 \cdot 6$ \\
Non-dispensing: & & & \\
4 & 29299 & 26164 & $-10 \cdot 7$ \\
5 & 30997 & 27867 & $-10 \cdot 1$ \\
6 & 29375 & 29375 & 0 \\
7 & 32892 & 31180 & $-5 \cdot 2$ \\
8 & 37232 & 38478 & $3 \cdot 4$ \\
& Non-fundholdingt & \\
Non-dispensing: & \multicolumn{3}{c}{} \\
9 & 20309 & 24360 & $20 \cdot 0$ \\
10 & 27268 & 30054 & $10 \cdot 2$ \\
11 & 33960 & 35057 & $3 \cdot 2$ \\
12 & 30763 & 35305 & $14 \cdot 8$ \\
13 & 31607 & 36893 & $16 \cdot 7$ \\
14 & 36295 & 38114 & $5 \cdot 0$ \\
15 & 34981 & 39445 & $12 \cdot 8$ \\
\end{tabular}

${ }^{\star}$ Fundholders whose previous spending was less than that of the family health services authority average had $50 \%$ of the difference added to indicative amount when converting this amount into drug budget. Budgets indicative amount when converting this amount into drug budget. Budgets
include the end of year supplements for changes to list size and changes include the end of year supplements for changes to list size and changes
to expensive drugs during the year that were given to four fundholding to expens

practices.
† Budgets and amounts spent exclude additions for container costs and subtractions for discounts allowed to dispensing general practitioners.

\section{Discussion}

One of the main attractions of the fundholding scheme for the practices which volunteered to join it was the opportunity to make budgetary savings in certain aspects of their clinical practice which could be reinvested in other aspects of patient care. It has always been apparent that the drugs element of fundholders' budgets offered the greatest potential for savings. ${ }^{7}$ Our study provides evidence that this scheme has indeed had an effect on prescribing costs.

Before the reforms the group of non-fundholding practices had the lowest total net cost of ingredients, the lowest number of items prescribed, and the highest percentage of generic drugs prescribed of the three groups. In terms of costs they were reasonably representative of local practices: only three of the seven were below the average level of spending in their family health services authority. By phase 2 their costs were 
higher than those of the fundholding practices. The financial incentives offered by the fundholding scheme proved to be more effective than the much weaker incentives to change prescribing patterns available to non-fundholders. It will be interesting to see whether the newer individual practice incentive schemes will have more effect. ${ }^{8}$

Historically, prescribing in general practice has been the main non-cash limited element in the NHS budget, and there were few incentives to restrict costs. The introduction of fundholding brings a proportion of prescribing costs within the cash limited budget; in the long run fundholding may reduce the national drugs bill, which has been growing by around $11 \%$ each year since $1987 . .^{9}$ It increased by $12 \cdot 3 \%$ during this study. Hospitals are tending to shift the costs of prescribing on to general practices, but we found no evidence of a differential effect on fundholders and non-fundholders.

The scope for reducing the number and cost of prescriptions issued without detriment to good patient care is believed to be considerable, ${ }^{810}$ so it was no surprise to find that many fundholding practices succeeded in making savings in their drugs budgets. However, these savings were not as large as the government might have hoped. Despite adopting several measures designed to rationalise their prescribing, none of the practices in our study was able to achieve a reduction in the net costs of ingredients. The fact that five fundholding practices were nevertheless able to make savings suggests that their drugs budgets were allocated generously. Fundholders took full advantage of the opportunity to negotiate various increases to their budgets, and the additions that were subject to the discretion of medical advisers to the family health services authorities varied considerably. This variation may have been appropriate as the aim was a flexible process of budget allocation taking "full account of the needs and circumstances of each practice," 11 but the process could be perceived as unfair by those who were not able to benefit from it by reinvesting the savings. The solution to this problem would be a revised system of budget allocation based on a needs weighted capitation formula, but the construction of a satisfactory formula is proving difficult. ${ }^{12}$

In conclusion, our study shows that general practitioners will modify their prescribing behaviour if offered sufficiently clear incentives. A true test of these reforms, however, will be to show that they lead to improvements in the efficiency, effectiveness, and equitable distribution of health care resources. As we

\section{Practice implications}

- General practitioners' prescribing costs have risen in real terms by $56 \%$ in the past decade

- Indicative prescribing schemes for non-fundholders and drug budgets for fundholders were introduced in the 1991 reforms as incentives to curb these increases

- This study found that in the year after implementation of these schemes fundholders had significantly lower increases in drug costs than non-fundholders

- Dispensing and non-dispensing fundholders increased the percentage of generic drugs that they prescribed whereas the non-fundholders did not

- Over $60 \%$ of the fundholding practices in the study made savings on their drug budgets

have argued previously, ${ }^{4}$ it is still too early to pass judgment.

We thank all those who have helped us with this study, particularly the partners and staff of the participating practices and the staff of the Prescription Pricing Authority; the family health services authorities in Berkshire, Buckinghamshire, Northamptonshire, and Oxfordshire; and the Oxford Regional Health Authority. The study was funded by the Oxford Regional Health Authority.

1 Chew R. Compendium of health statistics. 8th ed. London: Office of Health Economics, 1992

2 NHS Management Executive. Improving prescribing. London: Department of Health, 1990. (EL(90)P93.)

3 Secretaries of State for Health, Wales, Northern Ireland, and Scotland. Indicative prescribing budgets for general medical practitioners. London: HMSO, 1989. (NHS review working paper 4 .)

4 Coulter A, Bradlow J. Effect of NHS reforms on general practitioners' referral patterns. BMF 1993;306:433-7.

5 Morton-Jones T, Pringle M. Prescribing costs in dispensing practices. BMf 1993;306:1244-6.

6 Chew R, Griffin JP. Growth in prescription medicines expenditure, $A B P I$ Briefing 1992; July: 1-4.

7 Weiner JP, Ferriss DM. GP budget holding in the UK: lessons from America. London: King's Fund Institute, 1990

8 Jones T. The GP drugs bill: is the indicative prescribing scheme working? Primary Care Management 1993;3:5-6.

9 Department of Health. Statistical Bulletin 1993; No 8 (Aug)

10 Harris C. Patterns of prescribing. In: Griffin J, ed. Factors influencing clinical decisions in general practice. London: Office of Health Economics, 1991.

11 NHS Management Executive. Indicative prescribing scheme: guidance on the financial framework and other technical issues. London: Department of Health, 1991. (EL(91)12.)

12 Coulter A. Fundholding general practices. BMF 1992;304:397-8.

(Accepted 12 October 1993)

\section{COPING WITH CHANGE IN GENERAL PRACTICE}

It would be comforting if all the changes required in general practice were based on reliable evidence from good empirical research. In the case of the new general practitioners' contract the evidence was either lacking or pointed in directions quite different from those proposed by the contract. Often, however, the evidence is simply not available, or is confused. We would argue, for example, that even in the absence of hard evidence counselling reduces morbidity or improves prognosis; counselling remains valuable because of what it says about the humane intentions of medical care. The practice of medicine cannot be driven by the evidence and rules of scientific inquiry alone. The doctor is not a clinical experimenter, but a healer. It is not only the provenance of change that is important but the openness with which that provenance is disclosed and discussed.

Change based on the vagaries of fashion is much less persuasive than change based on sound evidence. Fashion has played an important part in the development of twentieth century general practice. For the past 20 years primary care team work, educationalism (including role play and video consultation analysis), screening, health promotion, and performance review have all been fashionable. Although each of them has enhanced the character and complexity of modern British general practice, they were first and foremost fashions, with relatively short life spans. Most of them were driven by a small number of proselytising advocates (indeed one of us cannot be exonerated from much of this). In so far as the spread of the fashion has been experienced as growth and enlightenment, the changes were acceptable. But there remains the sense of being a slave to fashion. The violence of that term may explain much of the resentment and disdain expressed by general practitioners for the relatively innocent enthusiasms of academic bodies like the Royal College of General Practitioners.

From Mairi G B Scott and Marshall Marinker: Imposed change in general practice. In: Mike Pringle (ed), Change and Teamwork in Primary Care, 1993. Available from $B M \mathcal{F}$ bookshop, price $£ 7.95$. 